\title{
Research on Optimization of Sichuan Province National Territory Spatial Planning Based on Carbon Neutrality
}

\author{
Xuesong Han ${ }^{1}$, Huanggen $\mathrm{Gao}^{1}$, and Yuan Zheng ${ }^{1, *}$ \\ ${ }^{1}$ National Territory Spatial Planning Research Institute of Sichuan Province, Chengdu, Sichuan, China
}

\begin{abstract}
The functional structure of territorial space is an important factor affecting the regional carbon cycle. The article explores the interaction mechanism between the functional structure of territorial space and carbon sources and carbon sinks, constructs a model for measuring and calculating territorial spatial carbon sources and carbon sinks, and investigates land changes in Sichuan Province, etc. Based on the data, the spatial carbon emission and absorption of Sichuan from 2010 to 2017 were calculated, and the carbon source carbon aggregate amount, structural composition and intensity change trend were analysed. The results show that changes in the spatial land use structure of Sichuan are closely related to carbon emissions, and the increase in construction land is the main reason for the substantial increase in carbon emissions. Finally, in combination with the vision and goals of "carbon neutrality", relevant optimization suggestions were put forward for the land and space planning of Sichuan Province.
\end{abstract}

\section{Introduction}

The increase in carbon emissions is the main cause of disastrous weather and climate such as the greenhouse effect, heat waves, and sea level rise. In response to the above-mentioned problems, my country proposes to achieve the peak of carbon emissions by 2030 and the goal of achieving carbon neutrality by 2060 . The change in the structure of national land space and land use is an important factor affecting the carbon cycle, and it is also a carbon emission source second only to fossil fuels [1]. Land use change directly affects the distribution and structure of terrestrial ecosystems, and changes their carbon storage and carbon flux processes [2]. Therefore, combing through the inter-communication mechanism of carbon sources and carbon sinks in terrestrial space is useful for building a "carbon-neutral" country. Space is crucial. Scholars at home and abroad have conducted indepth studies on the impact of land use structure changes on the carbon cycle. Some scholars have studied the carbon emission effects of Zhejiang, Liaoning and other provinces [3-4], established the relationship between energy consumption and land use, and calculated the carbon emissions of different land use types. The article [5] calculated the carbon emissions of arable land, grassland and woodland in Shanghai, and used the VAR model and impulse response function to analyse the dynamic relationship between the area of construction land and carbon emissions in Shanghai. The article [6] uses the life cycle method to analyse the carbon emissions from building manufacturing, and proposes that the recycling of building materials is a new way to reduce carbon emissions.
Although the research on the effect of land use on carbon emissions has attracted widespread attention, the relevant research cannot fully adapt to the new development concept of land and space planning in the new era, and the domestic research objects are mainly concentrated in the central and eastern regions, and there is little research on Sichuan and other western provinces and cities. This study takes Sichuan Province as an example, analyses the changing trends of territorial and spatial carbon sources and carbon sinks over the years, and proposes relevant suggestions for optimizing the territorial space of Sichuan based on this, in order to provide a reference for promoting the implementation of the concept of carbon neutrality in territorial and spatial planning.

\section{Research Method}

\subsection{The relationship between carbon emissions and land}

The carbon emissions and carbon sinks produced by different territorial and spatial land structures are different. According to the Land Management Law, land is divided into agricultural land, construction land and unused land. The production of carbon dioxide (carbon source) in the territorial space comes from nature, but also from production and life. The types of land involved mainly include cultivated land in construction land and agricultural land; carbon dioxide absorption is mainly due to photosynthesis of vegetation such as forests and grasslands. The land types are mainly cultivated land, garden land, woodland and grassland.

\footnotetext{
*Corresponding author: songshu183@163.com kinocruz@163.com
} 
It should be noted that unused land mainly includes barren hills, grasses, sandy land, etc., and its carbon absorption capacity is relatively weak, so it is not included in this study. Secondly, in order to calculate the final net carbon emissions, set carbon emissions to be positive and carbon absorption to be negative.

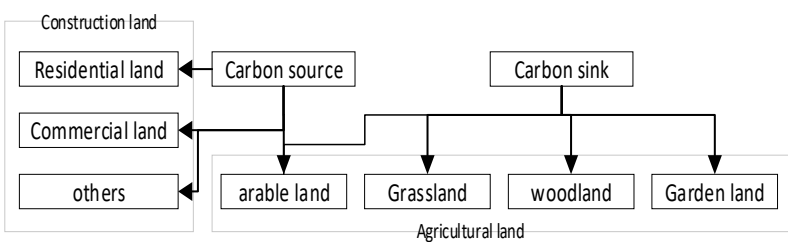

Fig. 1. The Relationship between Carbon Source Carbon Sink and Land Type

\subsection{Model building}

\subsubsection{Calculation of carbon emissions from construction land}

There are direct calculation methods and indirect calculation methods for the calculation of carbon emissions from construction land. The direct calculation method is based on the sum of the carbon dioxide emissions generated by various production and construction activities on the construction land; the indirect calculation method is based on the use of coal, natural gas and other energy consumption for various activities to convert into carbon emissions or according to the energy consumption standard of 10,000 yuan GDP Indirectly converted to carbon emissions. This time, the indirect calculation method is used to calculate the carbon emissions of construction land.

$$
C_{j}=G D P \times \alpha \times \gamma
$$

Where, $C_{j}$ : Carbon emissions from construction land, t; GDP: Domestic production gross value of secondary and tertiary industries, Unit: ten thousand yuan; $\alpha$ : Coal energy consumption per 10,000 yuan of GDP, ton per ten thousand yuan; $\gamma$ :Coal's carbon emission factor[7], $\gamma=$ $0.7476 \mathrm{t} / \mathrm{t}$.

\subsubsection{Cultivated land carbon emission calculation}

Cultivated land is both a carbon source and a carbon sink. When photosynthesis grows, crops will absorb carbon dioxide in the atmosphere. At the same time, the carbon emissions generated by fertilization of crops, mechanized operations, and irrigation of crops will also generate carbon emissions. Calculate as follows.

$$
C_{g p}=C_{f e i}+C_{j i}+C_{g u a n}
$$

Where, $C_{g p}$ : Cultivated land carbon emissions, tons; $C_{f e i}$ Carbon emissions from fertilization of cultivated land, $\mathrm{t} ; C_{j i}$ Carbon emissions from mechanized operations, tons; $C_{\text {guan }}$ Carbon emissions from irrigation operations, tons.

$$
C_{f e i}=N_{h} \times \delta_{h}
$$

Where, $N_{h}$ : Amount of fertilizer used in crops, tons; $\delta_{h}$ Fertilizer carbon emission factor, $\mathrm{g} / \mathrm{kg}$;

$$
C_{j i}=A_{n} \times \delta_{n}+W_{j} \times \delta_{j}
$$

Where, $A_{n}$ : Crop planting area, $\mathrm{hm}^{2} ; W_{j}$ :Total power of agricultural production machinery, $\mathrm{kW} ; \delta_{n}$ :Crop carbon emission factor, $\mathrm{t} / \mathrm{hm}^{2} ; \delta_{j}$ :Mechanical carbon emission factor, $\mathrm{t} / \mathrm{hm}^{2}$.

$$
C_{\text {guan }}=A_{g} \times \delta_{g}
$$

Where, $A_{g}$ : Crop irrigated area, $\mathrm{hm}^{2} ; \delta_{g}$ :Irrigation operation carbon emission factor, $\mathrm{t} / \mathrm{hm}^{2}$;

The relevant parameter data in the above formula refers to the literature [8].

\subsubsection{Cultivated land carbon absorption calculation}

The photosynthesis of crops can absorb carbon dioxide in the atmosphere, and different types of crops have different abilities to absorb carbon dioxide. The carbon absorption produced by cultivated land can be calculated according to the following formula.

$$
C_{g x}=\prod_{i=1}^{m} Q_{i} \times Y_{i} / H_{i}
$$

Where, $C_{g x}$ : Cultivated land carbon uptake, $\mathrm{t}$;

$Q_{i}$ : The i-th crop carbon absorption coefficient;

$Y_{i}$ : Yield of the i-th crop, 10,000 tons;

$H_{i}$ : Economic coefficient of the i-th crop.

Table 1. Economic Coefficient and Carbon Absorption Coefficient of Main Crops in Sichuan Province [9]

\begin{tabular}{|c|c|c|}
\hline $\mathrm{N}$ & $Q_{i}$ & $H_{i}$ \\
\hline Rice & 0.45 & 0.4144 \\
\hline Wheat & 0.40 & 0.4835 \\
\hline Corn & 0.40 & 0.4709 \\
\hline Sorghum & 0.35 & 0.4500 \\
\hline Millet & 0.40 & 0.4500 \\
\hline Sweet potato & 0.70 & 0.4226 \\
\hline Soybeans & 0.34 & 0.4500 \\
\hline Cotton & 0.10 & 0.4500 \\
\hline Peanut & 0.43 & 0.4500 \\
\hline
\end{tabular}

\subsubsection{Calculation of the carbon absorption of the garden}

The carbon dioxide absorption of the garden is mainly affected by the area of the garden, and the calculation method is as follows:

$$
C_{y}=A_{y} \times \delta_{y}
$$

Where, $C_{y}$ : The carbon emissions of the garden, $\mathrm{t}$;

$A_{y}$ : Garden area, $\mathrm{hm}^{2}$;

$\delta_{y}$ : Garden carbon absorption coefficient [3], $\delta_{y}=-1.7123 \mathrm{t} / \mathrm{hm}^{2}$. 


\subsubsection{Calculation of Carbon Uptake of Forest Land}

The carbon dioxide absorption of forest land is mainly affected by the area of forest land. The calculation method is as follows:

$$
C_{w}=A_{w} \times \delta_{w}
$$

Where, $C_{w}$ : Carbon emissions from forest land, $\mathrm{t} ; A_{w}$ : Forest area, $\mathrm{hm}^{2} ; \delta_{w}$ : Woodland carbon absorption coefficient [7], $\delta_{w}=-3.8096 \mathrm{t} / \mathrm{hm}^{2}$.

\subsubsection{Grassland carbon uptake}

The carbon dioxide absorption of grassland is mainly affected by the area of grassland. The calculation method is as follows:

$$
C_{c}=A_{c} \times \delta_{c}
$$

Where: $C_{\mathrm{c}}$ : The carbon emissions of the garden, $\mathrm{t} ; A_{c}$ : Garden area, $\mathrm{hm}^{2} ; \delta_{c}$ : Garden carbon absorption coefficient, $\delta_{c}=-0.021 \mathrm{t} / \mathrm{hm}^{2}$.

\subsubsection{Net carbon emissions}

The net carbon emission of regional land space is the sum of carbon emission and absorption of construction land, arable land, garden land, grassland, woodland, etc. The calculation method is as follows:

$$
C_{t}=C_{j}+C_{g p}+C_{g x}+C_{y}+C_{w}+C_{c}
$$

Where: $C_{t}$ : Net carbon emissions from land, t;

\section{Analysis of Land Carbon Source and Carbon Sink in Sichuan Province}

\subsection{Overview of the study area}

Sichuan is located in the inland of southwest China, with a land area of 486,000 square kilometres. It is an important ecological barrier for the upper reaches of the Yangtze and Yellow Rivers, as well as an important forest and pastoral area in my country. The land use types in Sichuan are rich and diverse, and the overall development intensity is low. Construction land accounts for 3.39\% of the country's land area, mainly concentrated in basin plains and hilly areas; cultivated land accounts for $11.87 \%$, concentrated in basin plains and low mountain and hilly areas; woodland and pasture The land accounts for $72.05 \%$, mainly distributed in the mountains around the basin and the western alpine plateau. Sichuan is a modern industrial base with the most complete industry categories and the strongest comprehensive strength in the western region.

\subsection{Data Sources}

The data of this research mainly comes from the data of the Sichuan Land Change Survey (2010 2017) and the "Statistical Yearbook of Sichuan Province" (2010 2018).

\subsection{Net carbon emissions}

According to the calculation model and the relevant statistical data of Sichuan Province, the carbon source emissions and carbon sink absorption of Sichuan from 2010 to 2017 are estimated. The main analysis results are as follows.

Table 2. 2010 2017 Sichuan Land Carbon Source Table

\begin{tabular}{cccc}
\hline \multirow{2}{*}{ Year } & \multicolumn{3}{c}{ Carbon source } \\
\cline { 2 - 4 } & Construction land & Arable land & Summary \\
\hline 2010 & 10470.3 & 557.7 & 11028.0 \\
2011 & 12847.2 & 577.8 & 13425.0 \\
2012 & 14649.6 & 599.1 & 15248.7 \\
2013 & 16351.7 & 628.8 & 16980.5 \\
2014 & 17759.5 & 649.0 & 18408.5 \\
2015 & 18732.1 & 678.9 & 19411.0 \\
2016 & 20600.1 & 697.0 & 21297.1 \\
2017 & 23236.8 & 718.9 & 23955.7 \\
\hline
\end{tabular}

Table 3. 2010 2017 Sichuan Land Carbon Sink Table

\begin{tabular}{cccccc}
\hline \multirow{2}{*}{ Year } & \multicolumn{5}{c}{ Carbon sink } \\
\cline { 2 - 6 } & $\begin{array}{c}\text { Arable } \\
\text { land }\end{array}$ & Garden & $\begin{array}{c}\text { Wood } \\
\text { land }\end{array}$ & Grass & Summary \\
\hline 2010 & -1354 & -131 & -8458 & -26 & -9969 \\
2011 & -1382 & -128 & -8454 & -26 & -9991 \\
2012 & -1392 & -128 & -8450 & -26 & -9995 \\
2013 & -1423 & -127 & -8447 & -26 & -10023 \\
2014 & -1417 & -127 & -8446 & -26 & -10016 \\
2015 & -1446 & -126 & -8443 & -26 & -10040 \\
2016 & -1463 & -125 & -8440 & -26 & -10053 \\
2017 & -1467 & -124 & -8435 & -26 & -10052 \\
\hline
\end{tabular}

\subsubsection{Changes in carbon sources and carbon sinks}

From the analysis of net carbon emissions, Sichuan's land carbon emissions and carbon absorption were generally in balance before 2010; Sichuan's land carbon emissions exceeded carbon absorption from 2010 to 2017, and the net carbon emissions showed a trend of increasing year by year.

From the analysis of the change trend of carbon emissions, the carbon emissions of Sichuan from 2010 to 2017 also showed a trend of increasing year by year. The main reason for the above changes is that with the economic and social development of Sichuan, the rapid expansion of urban construction land and the rapid growth of the secondary and tertiary industries have brought about a rapid increase in carbon emissions. 


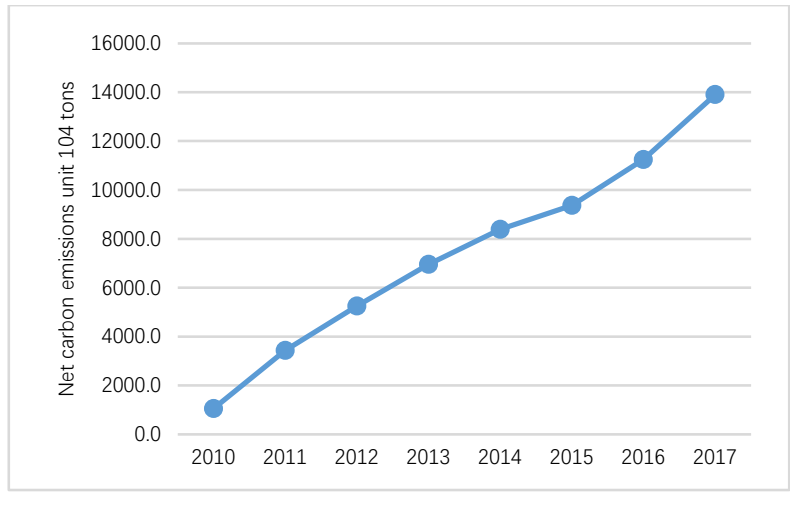

Fig. 2. 2010 2017 Sichuan Province Land Net Carbon Emissions Trend Chart

In addition, with the increase in the use of chemical fertilizers and the level of mechanization in arable land, the carbon emissions of arable land have also shown an increasing trend year by year.

From the analysis of changes in carbon absorption, the overall carbon absorption of Sichuan from 2010 to 2017 showed a steady trend of change. Among them, the carbon absorption of arable land increased slightly, the carbon absorption of garden land decreased slightly, and the carbon absorption of forest land and grassland remained unchanged as a whole.

\subsubsection{Carbon source and carbon sink composition analysis}

From the data analysis, it can be found that the carbon emissions generated by the construction land where the secondary and tertiary industries are located are the main source of carbon sources, and their contribution to carbon emissions exceeds $95 \%$, and the contribution rate of agricultural production carbon emissions does not exceed $5 \%$, as shown in Figure 2. The main reason for the above conclusions is that the transportation land, industrial and mining land, public service facility land and other activities consume a lot of energy and generate more carbon dioxide. In contrast, agricultural production of fertilizers, machinery, irrigation and other activities emit less carbon dioxide.

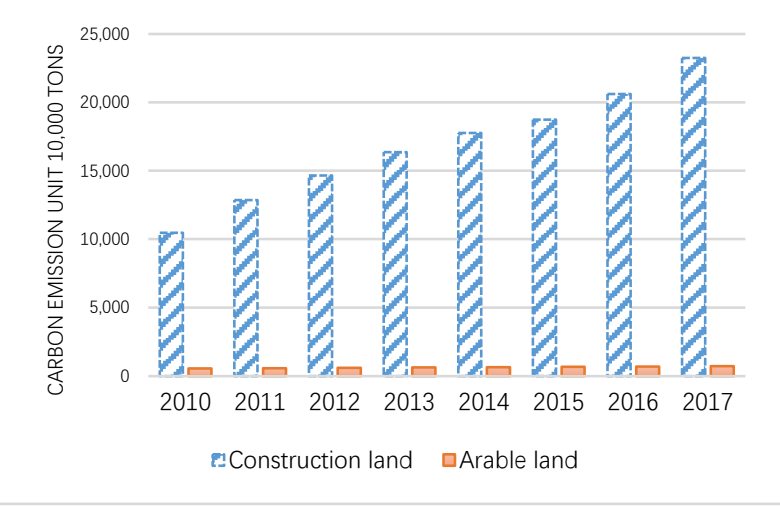

Fig. 3. 2010 2017 Sichuan Province Land Carbon Emissions Composition Map

The photosynthesis of vegetation in cultivated land, woodland, grassland, and gardens is the main reason for carbon absorption. Among them, forest land has the largest contribution to carbon absorption, with a contribution rate between $83 \%$ and $85 \%$; the contribution of cultivated land to carbon absorption ranks second. The contribution rate is between $13 \%$ and $15 \%$; the contribution rate of garden plots and grassland to carbon absorption is the smallest, and the contribution rate is between $1 \%$ and $2 \%$, as shown in Figure 3.

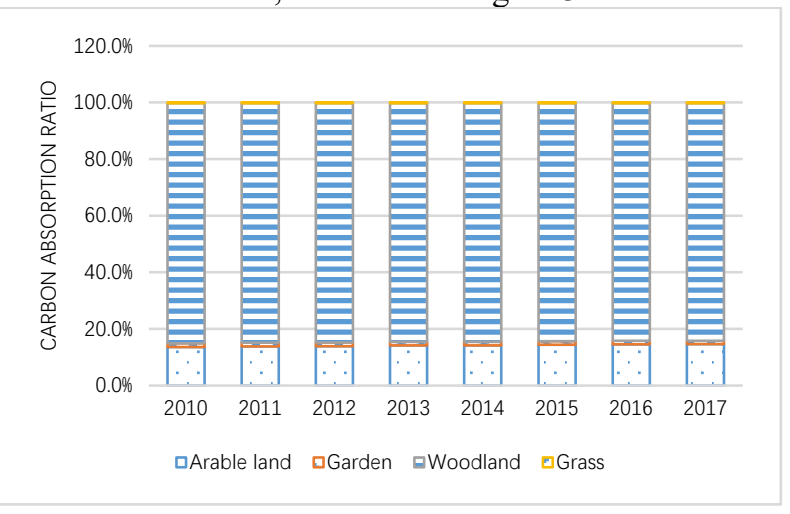

Fig. 4. 2010 2017 Sichuan Province Land Carbon Uptake Proportion Map

\subsubsection{Carbon source and carbon sink intensity analysis}

Taking 2016 as an example, the total carbon emission of construction land in Sichuan was 206 million tons, and the carbon emission intensity per unit area was $107.6 \mathrm{t} / \mathrm{hm}^{2}$; the carbon emission intensity per unit area of cultivated land was $1.03 \mathrm{t} / \mathrm{hm}^{2}$, and the carbon emission intensity per unit area of construction land was cultivated land. 104 times that of Sichuan is the main source of carbon emissions in Sichuan. Forest land and cultivated land are the main force for carbon absorption. Grassland and garden land have weak carbon sequestration capacity due to their own vegetation characteristics.

Table 4. 2016 Sichuan Land Carbon Source and Carbon Sink Intensity Table

\begin{tabular}{ccccc}
\hline & \multicolumn{2}{c}{ Carbon source } & \multicolumn{2}{c}{ Carbon sink } \\
\cline { 2 - 5 } Land type & Total & Intensity & Total & Intensity \\
& $10^{4}$ tons & $\mathrm{t} / \mathrm{hm}^{2}$ & $10^{4}$ tons & $\mathrm{t} / \mathrm{hm}^{2}$ \\
\hline $\begin{array}{c}\text { Construction } \\
\text { land }\end{array}$ & 20600 & 107.6 & - & - \\
Arable land & 697 & 1.03 & -1463 & -0.42 \\
Garden & - & - & -125 & -1.7123 \\
Woodland & - & - & -8440 & -3.8096 \\
Grass & - & - & -26 & -0.021 \\
\hline
\end{tabular}

\section{Suggestions for optimization of land and space planning}

From the analysis of Sichuan's carbon sources and carbon sinks, it can be found that the carbon emissions of the current land structure of Sichuan is greater than the carbon absorption, and the net carbon emissions are showing an increasing trend. In order to achieve the development goal 
of peaking carbon in 2030, it is recommended to optimize the land and space planning of Sichuan in the following aspects.

\subsection{Implement the ecological priority concept and enhance the carbon sequestration capacity of the ecological space}

Implement the concept of ecological priority, strengthen land and space planning and use control, strengthen the protection and restoration of forest land, grassland and other ecosystems, improve the capacity of ecological carbon sinks, effectively play the role of carbon sequestration of forests, grasslands, wetlands, and soil, and enhance ecosystem carbon sinks Increment; exploring the establishment of a carbon sink impact assessment system, a carbon sink loss compensation mechanism, or a carbon sink spatial compensation mechanism in the preparation of territorial and spatial planning and detailed territorial and spatial planning.

\subsection{Build a low-carbon space and optimize the spatial layout of the country}

\subsubsection{Optimize urban spatial layout}

To optimize the layout of urban land space, first of all, we need to improve the level of intensive use of land space in Sichuan and encourage the development of urban underground space. At the same time, it advocates the construction of a "narrow block, dense road network" urban road grid bureau, creating a community living circle of suitable scale, compact space, and complex functions, and promote the balance of work and housing. The goal is to reduce unnecessary commuting from the source.

\subsubsection{Optimize the industrial space layout}

In the process of industrial space layout, prioritize the layout of industrial spaces close to the industrial chain, shorten the transportation distance of raw materials for upstream and downstream enterprises, and reduce the carbon emissions of passenger and cargo transportation. At the same time, promote the integrated development of people, cities, industries, and transportation, and promote the integration of industrial parks and industrial parks. The combination of urban functions and the construction of a low-carbon and green industrial development space.

\subsubsection{Optimize the layout of blue and green spaces}

Following the natural landscape of cities and towns, green roads are used to string together natural resources such as mountains, forests, water bodies, wetlands, and pastoral areas to build a continuous stretch of blue and green spaces. The central urban area should appropriately increase the number of parks, green spaces and squares. The old urban area should be combined with the organic renewal of the city, plan pocket parks and street green spaces, increase the area of urban green space, and improve the carbon sequestration capacity. At the level of detailed planning, increase the green space rate index according to local conditions, Increase the green coverage of living communities, build a three-dimensional plant community structure dominated by trees, and improve the carbon sink capacity per unit of green area.

\subsection{Strengthen the total control of construction land}

The rapid increase in construction land is the main reason for the rapid increase in carbon emissions in Sichuan. The land space planning in the new era should be based on the assessment of carbon sources and carbon sinks, pay attention to the layout and planning of low-carbonoriented land space, and explore connotative, intensive, and green The new way of high-quality development of globalization. Explore carbon neutral development strategies for major construction land expansion, and innovate carbon compensation mechanisms for construction land expansion.

\subsection{Persist in public transport to guide urban development and create a green transportation system}

In terms of transportation planning, we insist on public transportation to guide urban development, lay out a public transportation system that integrates with urban functions in the overall land and space planning, optimize the layout of public hubs and stations, create an efficient and convenient green transportation system, and reduce the proportion of car trips. Reduce transportation carbon emissions.

\section{Analysis conclusion}

In the context of the increasing impact of the greenhouse effect on people's lives, explore the new era through optimizing land and space planning, strengthening land use planning and control, and reducing land and space carbon dioxide emissions, which will help China to achieve the carbon peak development goal by 2030 It is of great significance. Based on the quantitative analysis of the development of Sichuan's territorial and spatial carbon sources and carbon sinks, this paper puts forward the idea of territorial spatial development that should strengthen the construction of the ecosystem, which has a certain reference value for optimizing Sichuan's territorial and spatial planning.

\section{References}

1. Quay P D, Tilbrook B, Wong C S. Oceanic uptake of fossil fuel $\mathrm{CO}_{2}$ : carbon-13 evidence. Science, 256 (1992)

2. Gao Zhiqiang, Liu Jiyuan, Cao Mingkui, Li Kerang, Tao Bo. The impact of land use and climate change on the productivity and carbon cycle of ecosystems 
in the transitional area of agriculture and animal husbandry. Science in China, 10 (2004)

3. SHEN Wei, WENG Lingyan, LIU Binglin, et al. Carbon emission effect of land use in Zhejiang province. Resources \& Industries, 22 (2020)

4. YU Ting ting, HAN Chun lan, XU Guang cheng. Analysis on carbon source and carbon sink of different land use types of Liaoning province. Guangdong Agricultural Sciences 2(2012)

5. Caimiao Miao, Wukai Ya. Relationship between construction land expansion and carbon emissions of land use in Shanghai city. Resource Development \& Market 34(2018)

6. Frank G Collins. Inclusion of Carbonation During the Life Cycle of Built and Recycled Concrete: Influence on Their Carbon Footprint. The International Journal of Life Cycle Assessment, 15(2010)

7. Guoqun XU, Zeyuan LIU, et al. Decomposition model and empirical study of carbon emissions for china, 1995-2004. Chia population, resources and environment, 16(2006)

8. WEST T O, MARLAND G . A synthesis of carbon sequestration, carbon emissions, and net carbon flux in agriculture: comparing tillage practices in the UnitedStates.Agriculture,Ecosystems \& Environment, 91(2002)

9. IPCC. IPCC Guidelines for national Greenhouse Gas Inventories CJ Reference Manual, 195 